\title{
In vitro infection of aortic endothelial cells by caprine arthritis encephalitis virus enhances in vitro transmigration of peripheral blood leukocytes and modulates their phenotypic expression
}

\author{
Nadège Milhau ${ }^{\mathrm{a}}$, Claire Bellaton ${ }^{\mathrm{a}, \mathrm{b}}$, Sabine BALLEYdieR ${ }^{\mathrm{a}}$, \\ Marjorie GAONACH ${ }^{\mathrm{a}}$, Christian LE JAN ${ }^{\mathrm{a} *}$ \\ a UMR 754, Rétrovirus et Pathologie comparée, INRA/ENVL/UCBL, Université Claude Bernard, \\ 50 avenue Tony Garnier, 69366 Lyon Cedex 07, France \\ ${ }^{\mathrm{b}}$ École Pratique des Hautes Études, Laboratoire Interactions cellulaires : rétrovirus et cancer, \\ Université Claude Bernard, 50 avenue Tony Garnier, 69366 Lyon Cedex 07, France
}

(Received 28 June 2002; accepted 2 December 2002)

\begin{abstract}
Infection of goats by caprine arthritis-encephalitis virus (CAEV) provides a convenient example of the infiltration of various tissues by leukocytes following a natural lentiviral infection. This event is important in determining organ susceptibility and local immunity. Caprine vascular endothelial cells are susceptible to infection by CAEV in vitro, so we have investigated the consequences of this infection on the transmigration of uninfected leukocytes in an in vitro model. After in vitro infection by CAEV or stimulation by TNF $\alpha$, the endothelial cells allowed the passage of tenfold more leukocytes from uninfected donors than did the uninfected endothelial cells. The transmigrating leukocytes were enriched in $\mathrm{CD}^{+}$lymphocytes, and the leukocytes appeared to have been activated during transmigration, as demonstrated by their expression of IL2R, MHC class II antigens and gamma-delta T-lymphocyte markers. $\mathrm{CD}^{+}, \mathrm{CD}^{+}$and B-lymphocytes all proliferated in culture after transmigration. These results suggest that any possible infection or specific stimulation of endothelia in an infected animal could profoundly influence the choice of target organs and could activate the cells involved in local mucosal immune responses.
\end{abstract}

caev / endothelial cell / leukocyte / transmigration / in vitro

\section{INTRODUCTION}

Across the world, a large number of domestic sheep and goats are infected by small ruminant lentiviruses. MaediVisna virus was first isolated from sheep and Caprine arthritis-encephalitis virus (CAEV) from goats, but both viral types may infect either host. A major transmission route involves dam-to-offspring passage through infected cells in milk and colostrum. The virus infects cells of the monocyte-macrophage lineage, but the numbers of infected circulating monocytes can fluctuate over time, sometimes falling to virtually undetectable levels. In goats, a

* Correspondence and reprints

Tel.: (33) 04372876 18; fax: (33) 04372876 05; e-mail: lejan@univ-lyon1.fr 
rise in numbers of circulating infected cells usually accompanies the onset of lactation. The virus persists for life after infection, but many infected animals never develop clinical disease. When lesions occur, they are accompanied by leukocyte infiltration of the target organs, with the formation of lymphoid follicles enriched in $\mathrm{CD} 8^{+}$lymphocytes $[3,7,19,28]$. Serum antibodies appear after infection, but they are poorly neutralising or of low affinity [2]. Specific $\mathrm{CD}^{+}$cytotoxic $\mathrm{T}$ cells also appear in the blood [13].

Small ruminant lentiviruses typically provoke inflammatory lesions in specific organs of a proportion of infected animals, but only few infiltrating cells express the virus. The lymphoid follicles that develop appear to result from a general stimulation of the lymphoid cells rather than from an antigen-specific reaction, but few details of the control of virus expression and the development of local immunity to CAEV have been elucidated. We have therefore examined the initial steps of adhesion of leukocytes to the vascular endothelium and transmigration in vitro as a preliminary to understanding the tissue domiciliation of leukocytes in the infected goat. In this system we have compared the effect on leukocyte adhesion of infecting aortic endothelial cells with CAEV with that of treatment with TNF $\alpha$, an initiator of the sequence of events leading to expression of the endothelial cell surface molecules involved in leukocyte transmigration. Viral infection has frequently been shown to activate endothelial cells and thereby affect leukocyte adhesion, and the lentiviruses HIV and SIV are known to infect endothelial cells [1, 15, 27]. Activation of human endothelial cells by West Nile virus results in increased expression of MHC class II molecules and of adhesion molecules [24]. We have observed that similar changes occur in small ruminant endothelial cell infected in vitro by CAEV [12], and such changes should affect both leukocyte adhesion and subsequent behaviour because endothelial cells can express chemokines and cytokines such as IL-10, IL-6 and IL-8 [6].

In the present work blood leukocytes from uninfected goats were allowed to migrate through endothelial cells. The system does not require a homologous origin of the endothelial cells and leukocytes (see for example [11]). We find that the effect of infection of endothelial cells by CAEV is comparable to their treatment by $\mathrm{TNF} \alpha$, the natural initiator of the vascular inflammatory response, in promoting transmigration of blood leukocytes. The transmigrating cell population differed in both composition and physiological status from the input blood cells.

\section{MATERIALS AND METHODS}

\subsection{Animals}

All animals providing cells for this study came from breeding stock with a confirmed history of absence of CAEV infection by both ELISA serology and PCR examination of peripheral blood leukocytes [5]. Aortic endothelial cells were collected at autopsy from anaesthesied four newborn kids and blood was withdrawn by venipuncture into EDTA as required from multiparous Saanen goats does for preparation of blood leukocytes.

\subsection{Antibodies}

A panel of nine monoclonal antibodies, purchased from Veterinary Medical Research and Development (VMRD Inc, Pullman, WA, USA), were used to characterise peripheral blood leukocyte populations and to estimate their activation: GC1A (CD4), CACT80 (CD8), BAQ155A (B-B4), MM61A (CD14), BAQ4A (WC1N2), CACT116A (CD25), CAT82A (MHC Class II), CACT 63A (A2/T 63A) and CACT26A (A2/T 26A). These antibodies were used at a dilution of 1:75 vv in PBS containing $1 \%$ foetal calf serum (FCS). 
Endothelial cells were characterised using a polyclonal rabbit antiserum to human von Willebrand factor (A0082; Dako,Trappes, France), diluted 1:100 as above, and their activation estimated with a 1:500 dilution of the HAE2-1 monoclonal antibody to human Vascular Cell Adhesion Molecule-1 (VCAM-1).

\subsection{Preparation of stock cultures of aortic endothelial cells}

As described previously [12], cells were scraped from the inner surface of the abdominal aortas of four newborn kids with a scalpel blade into $25 \mathrm{~cm}^{2}$ plastic culture flasks (Biocoat collagen I cellware; Beckton Dickinson, Grenoble, France) in RPMI 1640 medium supplemented with $20 \%$ heat-inactivated FCS, sodium pyruvate (1 mM; Gibco, Life Technologies, CergyPontoise, France), L-glutamine (2 mM; Boehringer-Mannheim, Meylan, France), endothelial cell growth factor (ECGF; $100 \mu \mathrm{g} / \mathrm{mL}$; Boehringer), heparin $(50 \mu \mathrm{g} / \mathrm{mL}$; Sigma, St Quentin Fallavier, France), penicillin (100 U/mL; Boehringer-Mannheim), streptomycin $(100 \mu \mathrm{g} / \mathrm{mL}$; Boehringer Mannheim) and amphotericin B $(2.5 \mu \mathrm{g} / \mathrm{mL}$; Gibco). Cells were passaged at confluence in medium as above containing $10 \%$ FCS, and stored in liquid nitrogen after verification at the second or third passage. Cells used for subsequent experiments contained $>95 \%$ endothelial cells as estimated by their expression of von Willebrand factor (Envision + Peroxidase AEC, Dako), responded to stimulation with TNF $\alpha$ by expression of VCAM-1 and were infectable by CAEV.

\subsection{Culture of endothelial cells on membrane inserts}

Aortic endothelial cells were seeded into $25 \mathrm{~cm}^{2}$ culture flasks in supplemented RPMI 1640 medium as above, containing $20 \%$ FCS, then passaged at confluence in medium containing 10\% FCS until sufficient cells had been obtained. Cells were not used after the 10th passage. Cells were then seeded onto semi-porous collagencoated membrane inserts (Biocoat p6, $3 \mu \mathrm{m}$; Beckton Dickinson) at approximately $10^{6}$ cells/insert and incubated at $37^{\circ} \mathrm{C}$ and $95 \%$ humidity until they achieved confluence. Where relevant, confluent cultures on the membranes were infected with CAEV strain 3112 at $1 \mathrm{TCID}_{50}$ (tissue culture $50 \%$ infectious dose)/cell overnight and medium was replaced next morning. These membranes were used for migration tests $4-6$ days post infection, when some $15-30 \%$ of cells expressed CAEV capsid antigen by immunolabelling [12] with anti p30 antibody CAEP5A1 (VMRD Inc). Other membrane cultures were stimulated by treatment with recombinant human $\mathrm{TNF} \alpha$ (Sigma) at $1 \mathrm{ng} / \mathrm{mL}$ of medium for $8 \mathrm{~h}$, after which the medium was replaced and the cells cultured for 4-6 days before testing in parallel with the infected cultures.

\subsection{Preparation of blood leukocytes and transmigration}

Peripheral blood mononuclear cells were prepared by centrifugation at $600 \times g$ for $45 \mathrm{~min}$ at room temperature through a Ficoll-histopaque gradient (Sigma) as previously described [12]. Leukocytes were resuspended at $1 \times 10^{7}$ cells $/ \mathrm{mL}$ in RPMI $10 \%$ FCS before use. For establishment of division kinetics, some aliquots were labelled with carboxyfluorescein diacetate succimidyl ester (CFSE; Molecular Probes Inc., Eugene, OR, USA). Cells were resuspended in PBS at $10^{7}$ cells $/ \mathrm{mL}$ and an equal volume of a $5 \mu \mathrm{M}$ solution of CFSE in PBS added for $10 \mathrm{~min}$ at room temperature in the dark [25]. The labelled cells were washed twice in PBS then resuspended in RPMI $-10 \%$ FCS at $1 \times 10^{7}$ cells $/ \mathrm{mL}$.

Each series of comparisons of the numbers and populations of leukocytes migrating across untreated, $\mathrm{TNF} \alpha$-stimulated or CAEV-infected aortic endothelial cells was performed on endothelial cell cultures from a single donor goat. The leukocytes were, 
in contrast, derived from three different seronegative subjects. Each measurement was performed in triplicate. To test transmigration capacity, $2 \mathrm{~mL}$ of leukocyte suspension $\left(2 \times 10^{7}\right.$ cells $)$ were pipetted onto the confluent layers of uninfected, infected or stimulated endothelial cells on membrane inserts in 6-well culture plates. The leukocytes were allowed to adhere for $2 \mathrm{~h}$ at $37^{\circ} \mathrm{C}$, then the membranes were rinsed twice with medium and incubated overnight in fresh medium (RPMI - 10\% FCS). Transmigrated leukocytes were then recovered from the lower chamber, counted and labelled with appropriate antibody for phenotypic or functional analysis. Proliferation of the transmigrated cells was estimated using CFSE-labelled cells maintained in culture for 6 days post transmigration.

\subsection{Flow cytometry}

Transmigrated cells were recovered by centrifugation and resuspended in the appropriate dilution of antibody as listed above for $30 \mathrm{~min}$ at $4{ }^{\circ} \mathrm{C}$. After three washes in PBS containing $1 \%$ FCS, the pellet was resuspended in FITC-conjugated goat anti-mouse gamma globulin (Boehringer), or, in the case of von Willebrand antibody, rhodamine-conjugated goat anti-rabbit IgG $\mathrm{f}\left(\mathrm{ab}^{\prime}\right) 2$ fragment (Boehringer) for a further $30 \mathrm{~min}$ at $4{ }^{\circ} \mathrm{C}$. The labelled cells were again washed three times in PBS then fixed in 1\% paraformaldehyde and kept at $+4{ }^{\circ} \mathrm{C}$ until used. Cells were then passed through a FACSCalibur (Becton Dickinson) flow cytometer to evaluate uptake of the antibody on membrane antigens of cells gated on the leukocyte region. Cellular proliferation after 6 days culture was similarly evaluated using CFSE-labelled cells and analysis of the fluorescence profiles obtained.

\subsection{Blastogenesis}

Transmigrated leukocytes were maintained in culture for 6 days, and smears prepared by cytocentrifugation. Different leukocyte populations were distinguished by anti CD4, CD8 and B-B4 antibodies and peroxidase staining (Envision), and the proportion of cells with a blast morphology evaluated by optical microscopy.

\subsection{Data analysis and statistical analysis}

Each series of comparisons of the numbers and populations of leukocytes migrating across untreated, $\mathrm{TNF} \alpha$-stimulated or CAEV-infected aortic endothelial cells was performed on endothelial cell cultures from a single donor goat. The leukocytes were, in contrast, derived from three different seronegative subjects. Each measurement was performed in triplicate. Results, presented as mean \pm standard deviation, were compared using Student $t$ test.

\section{RESULTS}

The number of leukocytes migrating through untreated endothelial cell membranes was low; around $10^{5}$ cells for a p6 insert overnight, but increased tenfold $(P<$ 0.001 ) when the endothelial cells had been stimulated by $\mathrm{TNF} \alpha$ or infected with CAEV (Fig. 1). At the same time, the ratio of $\mathrm{CD}^{+}{ }^{+}$to $\mathrm{CD}^{+} \mathrm{T}$ lymphocytes, which was unchanged after migration through untreated endothelial cell membranes $(1.7 \pm 0.4$ vs. $2 \pm 0.4$ in PBMC), shifted to $0.9 \pm 0.2$ and $0.8 \pm 0.1$ after migration through stimulated or infected endothelial membranes respectively $(P<0.05$; Fig. 2$)$. As shown in Figure 3, the proportion of $\gamma \delta$ $T$ cells did not differ significantly from their $7 \%$ presence in peripheral blood. The absolute proportion of B lymphocytes, as evaluated by their expression of CD 19 (revealed by the B-B4 antibody) was difficult to establish with precision, because, unlike the CD4 and CD8 antigens, the cell population did not show distinct peaks of fluorescent and negative cells but showed wide variation in expression. The numbers 


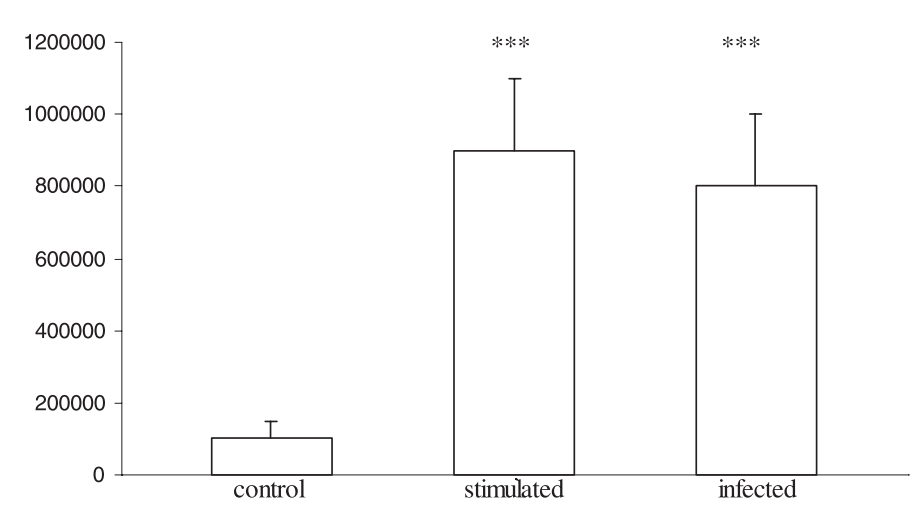

Figure 1. Number of leukocytes harvested after in vitro transmigration. After in vitro transmigration, leukocytes harvested in the lower well are counted in a Malassez chamber. Control: quiescent endothelial cells. Stimulated: endothelial cells treated with TNF- $\alpha$. Infected: endothelial cells infected in vitro by CAEV. *** Significant difference from control $(P<0.001)$.

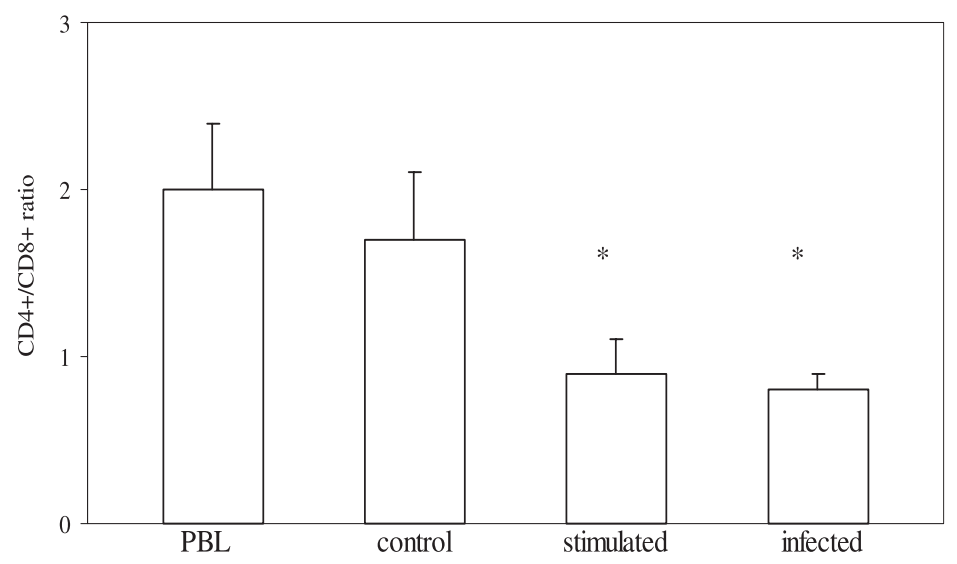

Figure 2. $\mathrm{CD}^{+} / \mathrm{CD} 8^{+}$ratio in $\mathrm{PBL}$ and in leukocyte populations after in vitro transmigration. The $\mathrm{CD} 4^{+} / \mathrm{CD}^{+}$ratio is measured by flow cytometry of leukocyte populations before and after in vitro transmigration. PBL: leukocytes prepared from peripheral blood. Control: quiescent endothelial cells. Stimulated: endothelial cells treated with TNF- $\alpha$. Infected: endothelial cells infected in vitro by CAEV. * Significant difference between PBL or control $(P<0.05)$.

of B-cells estimated were therefore strongly dependant on the cutoff value chosen, and did not allow us to demonstrate significant differences after migration through control versus stimulated or infected endothelial membranes. In contrast, the fluorescence intensity of cells labelled with the B-B4 antibody was very significantly increased on cells that had migrated through the stimulated or infected membranes (Fig. 4).
This increase was accompanied by higher expression MHC class II antigens and perhaps CD 14, as compared with input PBMC or cells that had migrated through untreated endothelial membranes (Fig. 4). The proportion of monocytes rose from $8 \%$ in the input PBMC to $12 \%$ in cells migrating through control or infected endothelial membranes, and to $20 \%$ in cells passing through $\mathrm{TNF} \alpha$-stimulated 


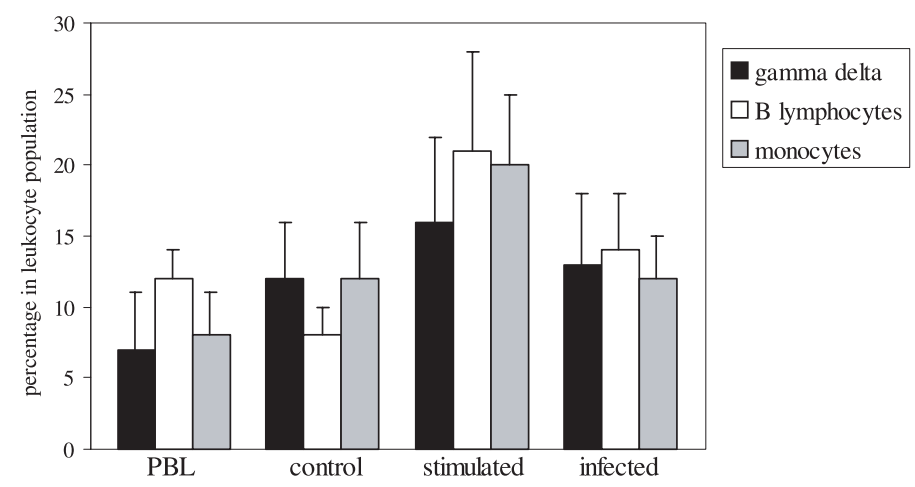

Figure 3. Proportions of $\gamma \delta \mathrm{T}$ lymphocytes, B lymphocytes and monocytes in leukocyte populations before and after in vitro transmigration. PBL: leukocytes prepared from peripheral blood. Control: quiescent endothelial cells. Stimulated: endothelial cells treated with TNF- $\alpha$. Infected: endothelial cells infected in vitro by CAEV.

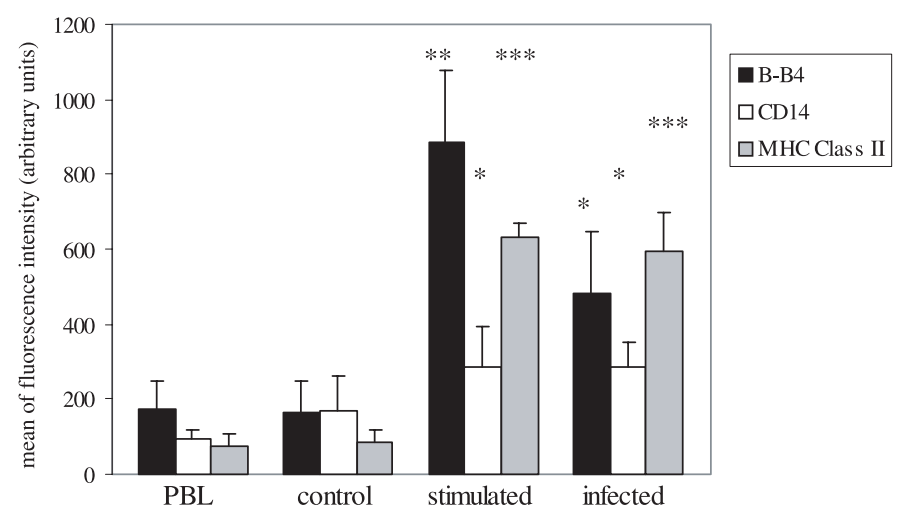

Figure 4. Fluorescence intensity after labelling with anti B-B4, CD14 and MHC Class II monoclonal antibodies. After labelling of leukocytes before and after in vitro transmigration by anti B-B4, CD14 and MHC Class II monoclonal antibodies, the means of fluorescence intensity were measured by flow cytometry analysis. PBL: leukocytes prepared from peripheral blood. Control: quiescent endothelial cells. Stimulated: endothelial cells treated with TNF- $\alpha$. Infected: endothelial cells infected in vitro by CAEV. * Significant difference from PBL $(P<0.05)$. ** Significant difference from PBL $(P<0.01)$. *** Significant difference from PBL $(P<0.001)$.

endothelial cells, these increases were, however, not significant (Fig. 3). The proportion of leukocytes expressing markers of activation, IL2 receptor, MHC Class II antigens or $\mathrm{A} 2 \mathrm{~T} / 63 \mathrm{~A}$ and $\mathrm{A} 2 \mathrm{~T} / 26 \mathrm{~A}$ for $\gamma \delta$ $\mathrm{T}$ lymphocytes, was significantly increased in transmigrating cells compared to input PBMC (Fig. 5). The effect was somewhat more pronounced in leukocytes that had transmigrated through CAEV-infected or, particularly, $\mathrm{TNF} \alpha$-stimulated endothelial membranes, but was already highly significant after passage through untreated endothelial cells. In short, after transmigration through untreated endothelial cell membranes, a greater proportion of 


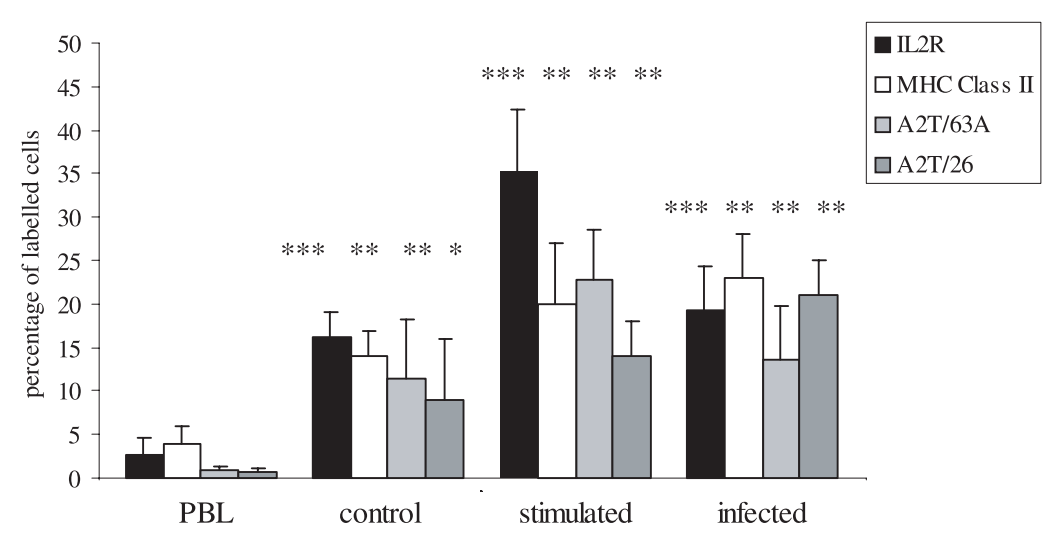

Figure 5. Proportions of leukocytes expressing IL2-R, MHC Class II and activated $\gamma \delta \mathrm{T}$ lymphocyte phenotypes in leukocyte populations before and after in vitro transmigration. The percentages of leukocytes labelled by monoclonal antibodies were evaluated by flow cytometry analysis, before and after in vitro transmigration. IL2R: leukocytes expressing IL2 receptor. Class II: leukocytes expressing MHC Class II antigens. A2T/63A and A2T/26A: leukocytes labelled by CACT63A and CACT26A monoclonal antibodies. PBL: leukocytes prepared from peripheral blood. Control: quiescent endothelial cells. Stimulated: endothelial cells treated with TNF- $\alpha$. Infected: endothelial cells infected in vitro by CAEV. * Significant difference from PBL $(P<0.05)$. $* *$ Significant difference from PBL $(P<0.01)$. $* * *$ Significant difference from PBL $(P<0.001)$.

peripheral blood leukocytes expressed MHC class II antigens, but the level of expression remained low. After passage through infected or stimulated endothelial membranes, the proportion of Class II expressing cells was little greater than after passage through untreated endothelia, but the intensity of expression was considerably higher (Fig. 4).

Cellular proliferation and blastogenesis were evaluated in the transmigrating cells after 6 days further culture. Microscopic examination of smears of non-adherent cells after migration through CAEVinfected endothelial membranes revealed numerous cells with blast morphology, and labelling with anti- CD4, CD8 or anti B-B4 antibodies and envision staining showed that all these categories of lymphocytes were involved (Fig. 6). Cytometric analysis of CFSE-labelled cells after transmigration and 6 days further culture showed multiple discrete peaks of fluorescence intensity, indicating that the cells had undergone division (Fig. 7).

\section{DISCUSSION}

The present study addresses the basic tissue interactions during infection by small ruminant lentiviruses, about which there are few experimental observations available. Knowledge of the mechanisms of local events in target organs is essential for the comprehension, and eventual control, of viral diffusion throughout the infected subject. Of particular interest is the mammary gland, a key site for viral infection of offspring. In vitro experiments are necessary to prepare for future in vivo investigations. We have previously established that in vitro infection of endothelial cells by CAEV increases adhesion of blood leukocytes [12], and now investigate the post-adhesion steps of transmigration and the fate of the transmigrating cells.

When the peripheral blood leukocytes from uninfected goats are put in contact with aortic endothelial cells, there is always a degree of transmigration, whether the 

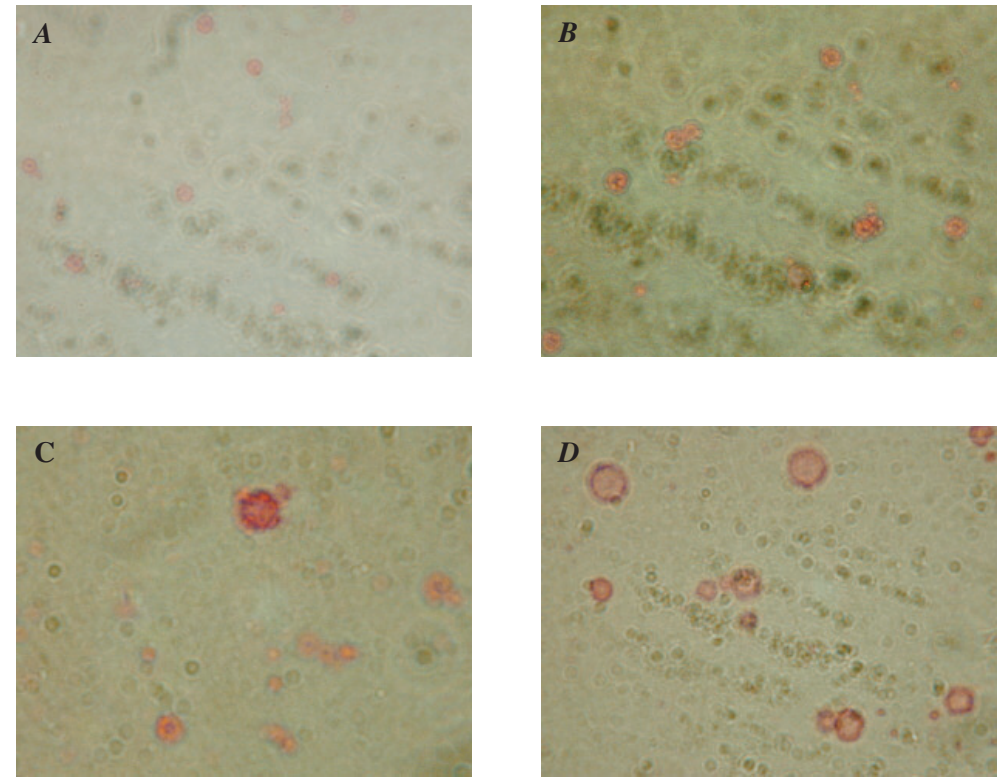

Figure 6. Microscopic observations of transmigrating leukocytes after a further 6 days culture. PBL were allowed to transmigrate through CAEV infected aortic endothelial cells, then maintained for 6 days in culture. Non-adherent leukocytes were then stained by ENVISION after labelling with different mAbs.

A: control leukocytes ; labelled by anti-CD4.

$\mathrm{B}$ : leukocytes after transmigration; labelled by anti-CD4.

C: leukocytes after transmigration; labelled by anti-CD8.

D: leukocytes after transmigration; labelled by anti-B-B4.

endothelial cells are untreated, infected by CAEV or stimulated with TNF- $\alpha$. However, only about $10^{5}$ leukocytes traverse quiescent endothelial cells on a P6 insert in $18 \mathrm{~h}$, compared to about $10^{6}$ through endothelial cells that had been stimulated with the pro-inflammatory cytokine TNF- $\alpha$, or infected with CAEV. Comparable results have been obtained in a similar system using HIV-1 infection [22]. It is noteworthy that this increase in transmigration is superior to the 2-fold increase in adhesion observed in our previous study. This probably reflects a predominance of the post rolling step events in the mechanism. Washing the monolayers after $90 \mathrm{~min}$ adhesion abrogates the secondary attraction and subsequent adhesion through produc- tion of TNF $\alpha$ and IL-1ß by adherent monocytes [14]. However, because our leukocytes are allowed to transmigrate for $18 \mathrm{~h}$, cytokine production by the endothelial cells might be involved $[18,20]$. Indeed, the enhancement of migration through infected or stimulated endothelial cells suggests that they play a major part in the process.

It is important to recognise that cells from all the populations of peripheral blood leukocytes participate in the transmigration, and that absolute numbers of $\mathrm{CD}^{+}$, $\mathrm{CD}^{+}, \gamma \delta \mathrm{T}$ lymphocytes, B lymphocytes and monocytes all increase in the subendothelial compartment of infected or stimulated endothelial membranes as compared to quiescent endothelial cells. The 


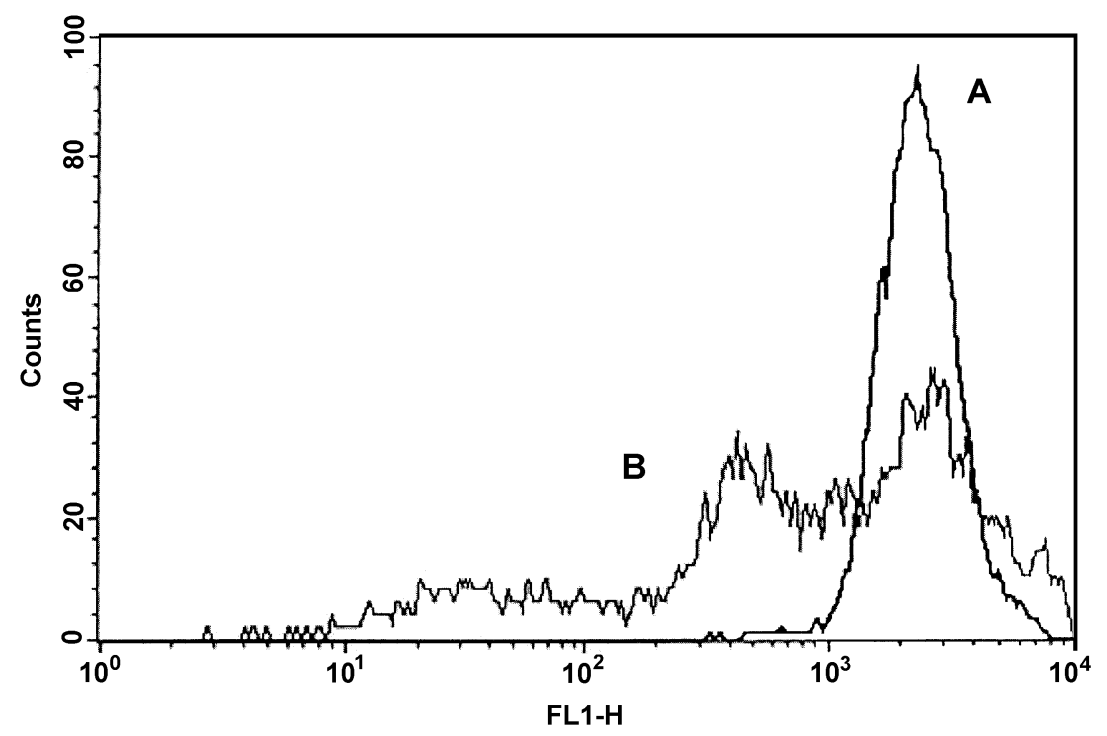

Figure 7. Fluorescence patterns of CFSE labelled peripheral blood leukocytes, controls or after in vitro transmigration through CAEV infected endothelial cells, at day 6 of culture. A: control leukocytes. B: leukocytes after in vitro transmigration through CAEV infected endothelial cells, at day 6 of culture.

$\mathrm{CD} 4^{+} / \mathrm{CD} 8^{+}$ratio decreases from $2: 1$ in the input leukocytes or after migration through quiescent cells to around 1:1 after transmigration through stimulated or infected cells. This shows a relative selection for $\mathrm{CD} 8^{+}$cells by activated endothelial cells. A similar enhancement of $\mathrm{CD}^{+}$cells from leukocytes of HIV-infected patients after transmigration through $\mathrm{TNF} \alpha$-stimulated endothelial cells [22]. Infiltrating lymphocytes in small ruminant lentiviral lesions show a slight preponderance of $\mathrm{CD}^{+}$cells, but it is not clear that this results from differential migration, because other factors such as selective cellular proliferation might be involved. In the blood, CD8 ${ }^{+}$cells are known to exert cytotoxic functions during lentiviral infections [17, 23], and might well behave similarly at the local level. We observed no proportional change in the percentage of monocytes after transmigration, however much larger numbers of monocytes, which are potential carriers of the CAEV provirus, migrate through infected than control endothelial membranes, and they become activated in the process. This could easily amplify the virus diffusion into the subendothelial compartment. Similarly, the proportion of B-lymphocytes and $\gamma \delta \mathrm{T}$ cells did not change upon transmigration, but again, then absolute number of these cells is much larger after transmigration through infected or stimulated than through control endothelial membranes. The B lymphocytes could therefore contribute to a local antibody production, although circulating anti CAEV antibodies are of low affinity [2].

The cells in the lower compartment are activated after transmigration. We observe strong induction of IL2R expression, an increase in the proportion of cells expressing class II antigens and an induction of activation markers in $\gamma \delta \mathrm{T}$ lymphocytes. A quantitative increase in the expression of CD14 and B-B membrane antigens results 
in higher fluorescence intensity after specific labelling. Activation of $\gamma \delta \mathrm{T}$ lymphocytes is observed using two monoclonal antibodies which preferentially label these cells $[8,9]$, and occurs within the $18 \mathrm{~h}$ transmigration period. The functions of $\gamma \delta \mathrm{T}$ lymphocytes in tissue lesions are not well known but they may contribute significantly [4].

Although activation during transmigration occurred in a similar fashion whether the endothelial cells were quiescent, stimulated or infected, perhaps through the production of IL-15 [18, 20], the absolute numbers were greatly increased after stimulation or infection. This results in a massive increase in the number of activated leukocytes in the subendothelial compartment of infected or activated, as compared to control, endothelial cells.

We observed active cell division among leukocytes that had migrated through an infected endothelial membrane by observing the modal decrease in fluorescence of CFSE-labelled cells over time [10, 21, 25]. We did not measure proliferation after migration through quiescent or $\mathrm{TNF} \alpha-$ stimulated endothelia, but, given the activation status of the transmigrating leukocytes under these circumstances, division probably occurs similarly. This indicates that the transmigrating cells are fully functional, and opens the possibility for clonal expansion in the tissue compartment.

Whatever the mechanisms involved, in vitro CAEV infection is responsible of the change in the pattern of migration from that observed through uninfected quiescent endothelia. Similar changes in the migration pattern occur after stimulation with TNF $\alpha$, suggesting that infection modifies cytokine secretion by the endothelial cell, contributing to the effect. The low level of transmigration through control endothelial cells shows, however, that production of $\mathrm{TNF} \alpha$ by adhering monocytes does not contribute significantly to the migration patterns observed.
It should be noted that our assay uses heterologous cells; aortic endothelia and leukocytes come from different animals. It remains possible that some of the effects on transmigration result from MHC differences between the cells used. The noninfected, unstimulated endothelia always induced low levels of transmigration, and these were not influenced by the different pairs of donors used for the experiments. In all cases stimulation or infection resulted in strong differences in the transmigration pattern suggesting that these treatments had a much stronger influence than any contribution from MHC differences.

The relevance of these results to in vivo infections will require further experimental demonstration. It is not established at present whether or not CAEV infects endothelial cells in natural infections, although other lentiviruses such as HIV-1 do $[16,26]$. The modulation of the characteristics of leukocytes after transmigration that we observe could contribute to the evolution of local immune reactions. Similarly, the activation of monocytes could contribute to viral diffusion in the target organ, because they are the chief reservoir of CAEV provirus, which is expressed on cellular activation.

In conclusion, we have shown that, after in vitro transmigration, the majority of leukocytes are activated and divide, and that in vitro infection by CAEV amplifies this phenomenom, and moreover modulate the phenotypic distribution of transmigrating leukocytes. These findings suggest further studies on specific functions after transmigration, in order to clarify the local mechanisms during lentiviral infection of tissues.

\section{ACKNOWLEDGEMENTS}

The authors thank Dr T.F. Tedder for his gift of the monoclonal antibody HAE2-1 and $\mathrm{Dr}$ T. Greenland for English language revision and fruitful discussions. 


\section{REFERENCES}

[1] Bagasra O., Lavi E., Bobroski L., Khalili K., Pestaner J.P., Tawadros R., Pomerantz R.J., Cellular reservoirs of HIV-1 in the central nervous system of infected individuals: identification by the combination of in situ polymerase chain reaction and immunohistochemistry, AIDS 6 (1996) 573-585.

[2] Bertoni G., Hertig C., Zahno M.L., Vogt H.R., Dufour S., Cordano P., Peterhans E., Cheevers W.P., Sonigo P., Pancino G., B-cell epitopes of the envelope glycoprotein of caprine arthritis-encephalitis virus and antibody response in infected goats, J. Gen. Virol. 81 (2000) 2929-2940.

[3] Cadoré J.L., Greenland T., Cordier G., Guiguen F., Mornex J.F., Histogenesis of the pulmonary lesions in the course of visna maedi virus-induced pneumonia, Vet. Res. 27 (1996) 419-426.

[4] Carding S.R., Egan P.J., The importance of gamma delta cells in the resolution of pathogen-induced inflammatory immune responses, Immunol. Rev. 173 (2000) 98-108.

[5] Chebloune Y., Karr B., Sheffer D., Leung K., Narayan O., Variations in lentiviral gene expression in monocyte-derived macrophages from naturally infected sheep, J. Gen.Virol. 77 (1996) 2037-2051.

[6] Chen C.C., Manning, A.M., TGF-beta, IL-10 and IL4 differentially modulate the cytokineinduced expression of IL-6 and IL-8 in human endothelial cells, Cytokine 8 (1996) 58-65.

[7] Clements J.E., Zink M., Molecular biology and pathogenesis of animal lentivirus infections, Clin. Microbiol. Rev. 9 (1996) $100-117$

[8] Davis W.C., Brown W.C., Hamilton M.J., Wyatt C.R., Orden J.A., Khalid A.M., Naessens J., Analysis of monoclonal antibodies specific for the gamma delta TCR, Vet. Immunol. Immunopathol. 52 (1996) 275283.

[9] Davis W.C., Naessens J., Brown W.C., Ellis J.A., Hamilton M.J., Cantor G.H., Barbosa J.I.R., Ferens W., Bohach G.A., Analysis of monoclonal antibodies reactive with molecules upregulated or expressed only on activated lymphocytes, Vet. Immunol. Immunopathol. 52 (1996) 301-311.

[10] Krupnick A.S., Kreisel D., Szeto W.Y., Popma S.H., Amin K.M., Moore J.S., Rosengard B.R., Multiparameter flow cytometric approach for simultaneous evaluation of $\mathrm{T}$ lymphocyte-endothelial cell interactions, Cytometry 46 (2001) 271-280.

[11] Lafrenie R.M., Wahl L.M., Epstein J.S., Heweltt I.K., Yamada K.M., Dhawan S., HIV-1 Tat protein promotes chemotaxis and invasive behavior by monocytes, J. Immunol. 57 (1996) 974-977.

[12] Le Jan C., Greenland T., Gounel F., Balleydier S., Mornex J.F., Activation of small ruminant aortic endothelial cells after in vitro infection by caprine arthritis encephalitis virus, Res. Vet. Sci. 69 (2000) 225-231.

[13] Lichtensteiger C.A., Cheevers W.P., Davis W.C., $\mathrm{CD} 8^{+}$cytotoxic T lymphocytes against antigenic variants of caprine arthritis-encephalitis virus, J. Gen. Virol. 74 (1993) 2111 2116 .

[14] Lidington E.A., McCormack A.M., Yacoub M.H., Rose M.L., The effects of monocytes on the transendothelial migration of $\mathrm{T}$ lymphocytes, Immunology 94 (1998) 221-227.

[15] Mankowski J.L., Splelman J.P., Ressetar H.G., Standberg J.D., Laterra J., Carter D.L., Clements J.E., Zink M.C., Neutrovirulent simian immunodeficiency virus replicates productively in endothelial cells of the central nervous system in vivo and in vitro, $\mathrm{J}$. Virol. 68 (1994) 8202-8208.

[16] Nottet H.S., Persidsky Y., Sasseville V.G., Nukuna A.N., Bock P., Zhai Q., Sharer L.R., McComb R.D., Swindelles S., Soderland C., Gendelman H.E., Mechanisms for the transendothelial migration of HIV-1 infected monocytes into brain, J. Immunol. 156 (1996) 1284-1295.

[17] Ogg G.S., Kostense S., Klein M.R., Jurriaans S., Hamann D., McMichael A.J., Miedema F., Longitudinal phenotypic analysis of human immunodeficiency virus type 1-specific cytotoxic T lymphocytes: correlation with disease progression, J. Virol. 73 (1999) 9153 9160.

[18] Oppenheimer-Marks N., Brezinschek R.I., Mohamadzadeh M., Vita R., Lipsky P.E., Interleukin 15 is produced by endothelial cells and increases the transendothelial migration of T Cells in vitro and in the SCID Mouse-Human Rheumatoid Arthritis Model in vivo, J. Clin. Invest. 101 (1998) 12611272.

[19] Pépin M., Vitu C., Russo P., Mornex J.F., Peterhans E., Maedi-Visna virus infection in sheep: a review, Vet. Res. 29 (1998) 341-367.

[20] Sancho D., Yanez-Mo M., Tejedor R., Sanchez-Madrid F., Activation of peripheral blood $\mathrm{T}$ cells by interaction and migration through endothelium: rôle of lymphocyte function antigen-1/intercellular adhesion 
molecule-1 and interleukin-15, Blood 93 (1999) 886-896.

[21] Sathiyaseelan T., Baldwin Cl., Evaluation of cell replication by bovine $\mathrm{T}$ cells in polyclonally activated cultures using carboxyfluorescein succinimidyl ester (CFSE) loading and flow cytometric analysis, Res. Vet. Sci. 69 (2000) 275-281.

[22] Saukkonen J.J., Furfaro S., Mahoney K.M., Strieter R.M., Burdick M., Wright E.A., Kornfeld H., Berman J.S., In vitro transendothelial migration of blood $\mathrm{T}$ lymphocytes from HIV-infected individuals, AIDS 11 (1997) 1595-1601.

[23] Sewell A.K., Price D.A., Oxenius A., Kelleher A.D., Phillips R.E., Cytotoxic T lymphocyte responses to human immunodeficiency virus: control and escape, Stem Cells 18 (2000) 230-244.

[24] Shen J., T-TO S.S., Schrieber L., King N.J., Early E-selectin,VCAM-1, ICAM-1, and late major histocompatibility complex antigen induction on human endothelial cells by flavivirus and comodulation of adhesion mole- cule expression by immune cytokines, J. Virol. 71 (1997) 9323-9332.

[25] Wells A.D., Gudmundsdottir H., Turka L.A., Following the fate of individual T cells throughout activation and clonal expansion. Signals from T cell receptor and CD28 differentially regulate the induction and duration of a proliferative response, J. Clin. Invest. 15 (1997) 3173-3183.

[26] Wiley A.C., Schrier R.D., Nelson J.A., Lampert P.W., Oldstone M.B., Cellular localization of human immunodeficiency virus infection within the brain of acquired immune deficiency syndrome patients, Proc. Natl. Acad. Sci. USA 83 (1986) 7089-7093.

[27] Woodroffe S.B., Garnett H.M., Danis V.A., Interleukin-1 production and cell-activation response to cytomegalovirus infection of vascular endothelial cells, Arch. Virol. 133 (1993) 295-308.

[28] Zink M.C., Johnson L.K., Pathobiology of lentivirus infection of sheep and goats, Virus Res. 32 (1994) 139-154. 